\title{
Canon y regalías mineras: situación actual y propuesta de politicas para su aplicación eficiente
}

\section{Canon and Mining Regulations: Current Situation and Proposal of Policies for its Efficient Application}

\author{
María Isabel Medrano Sánchez, ${ }^{*}$ Jessica Karina Obeso Cuadra, ${ }^{* *}$ \\ Geraldo Morón Paredes, ${ }^{* * *}$ José Luis Masías Vidal,**** \\ Wendy Lidia Moreano Márquez, ${ }^{* * * * *}$ María Eugenia García Segovia, ${ }^{* * * * * *}$ \\ José Coveñas Lalupu ******
}

http://dx.doi.org/10.21503/lex.v16i22.1664

Abogada. Magíster en Derecho de la Minería, que incluyó curso de extensión universitaria en Harvard University. Doctorando en Medio Ambiente y Desarrollo Sostenible. Coordinadora de cursos especializados en Minería, Seguridad y Salud Ocupacional, Comunidades y Medio Ambiente. Co-autora del Libro La concesión minera y diversos artículos sobre minería y medio ambiente.

Correo electrónico: isabel@medrano.pe

** Abogada, magíster en Derecho de la Minería, con especialización en Derecho Ambiental y Derecho Minero e Hidrocarburos. Docente de pregrado de los cursos de Derecho Minero y Derecho Ambiental. Expositora de diplomados y cursos de especialización en Minería, Medio Ambiente, Seguridad y Salud Ocupacional y Responsabilidad Social a nivel de postgrado. Correo electrónico: jessicaobesoc@gmail.com

*** Ingeniero metalúrgico. Segunda especialización en Medio Ambiente, Desarrollo Sostenible y Recursos Naturales. Especialización en Alta Gerencia. MBA. Expositor de diplomados y cursos de especialización en Medio Ambiente, Desarrollo Sostenible, Seguridad y Sistemas Integrados de Gestión a nivel de postgrado.

Correo electrónico: gmph26@hotmail.com

**** Ingeniero ambiental. Maestro en Docencia Universitaria y Gestión Educativa. Especialista en Monitoreo y Evaluación de la Calidad Ambiental y en Seguridad y Salud en el Trabajo. Coordinador académico y docente de la Escuela de Ingeniería Ambiental de la Universidad Alas Peruanas.

Correo electrónico: j_masias@uap.edu.pe

***** Ingeniera civil con maestría en Ingeniería Civil con mención en Gestión y Gerencia en la Construcción. Egresada de la maestría en Ingeniería Vial y doctorando en Medio Ambiente y Desarrollo Sostenible. Experiencia en el Sector Público en temas de transporte y gestión vial en vías nacionales.

Correo electrónico: wendymoreanom@hotmail.com

****** Arquitecta con estudios de maestría en Gestión Pública, delegada titular por parte del Colegio de Arquitectos del Perú en la Comisión Técnica de Edificaciones del Centro Histórico de Lima. Docente de la Facultad de Arquitectura y Urbanismo de la Universidad Privada del Norte de los cursos de Urbanismo Sostenible II y III. Amplia experiencia en Gobiernos locales en desarrollo urbano.

Correo electrónico: mariaeugenialourdes@yahoo.com

Ingeniero industrial. Primera promoción de la maestría y primera promoción de doctores de Ingeniería Industrial del Perú de la UNFV. Senior Operation Systems (OSP) Researcher (Massachusset Instituto of Innovation and Reinvention). Conferencista nacional e internacional en temas de medio ambiente, responsabilidad social y cultural. Premiado por la Unesco Puerto Rico. Embajador de la paz mundial con sede en Ginebra (Suiza). Miembro del Colegio y de la Sociedad de Ingenieros del Perú. Investigador en temas académicos.

Correo electrónico: jocola2003@gmail.com

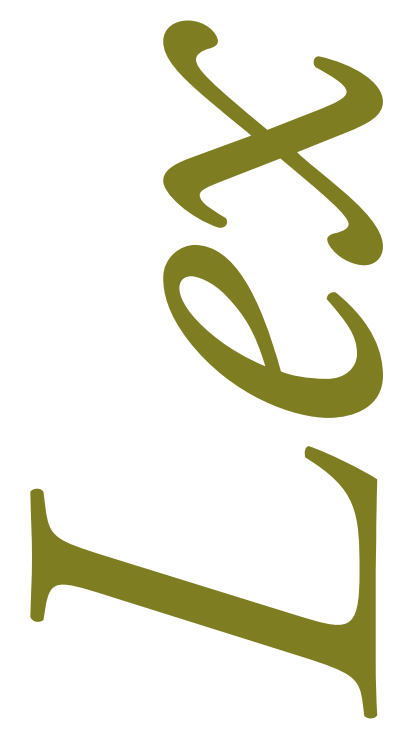




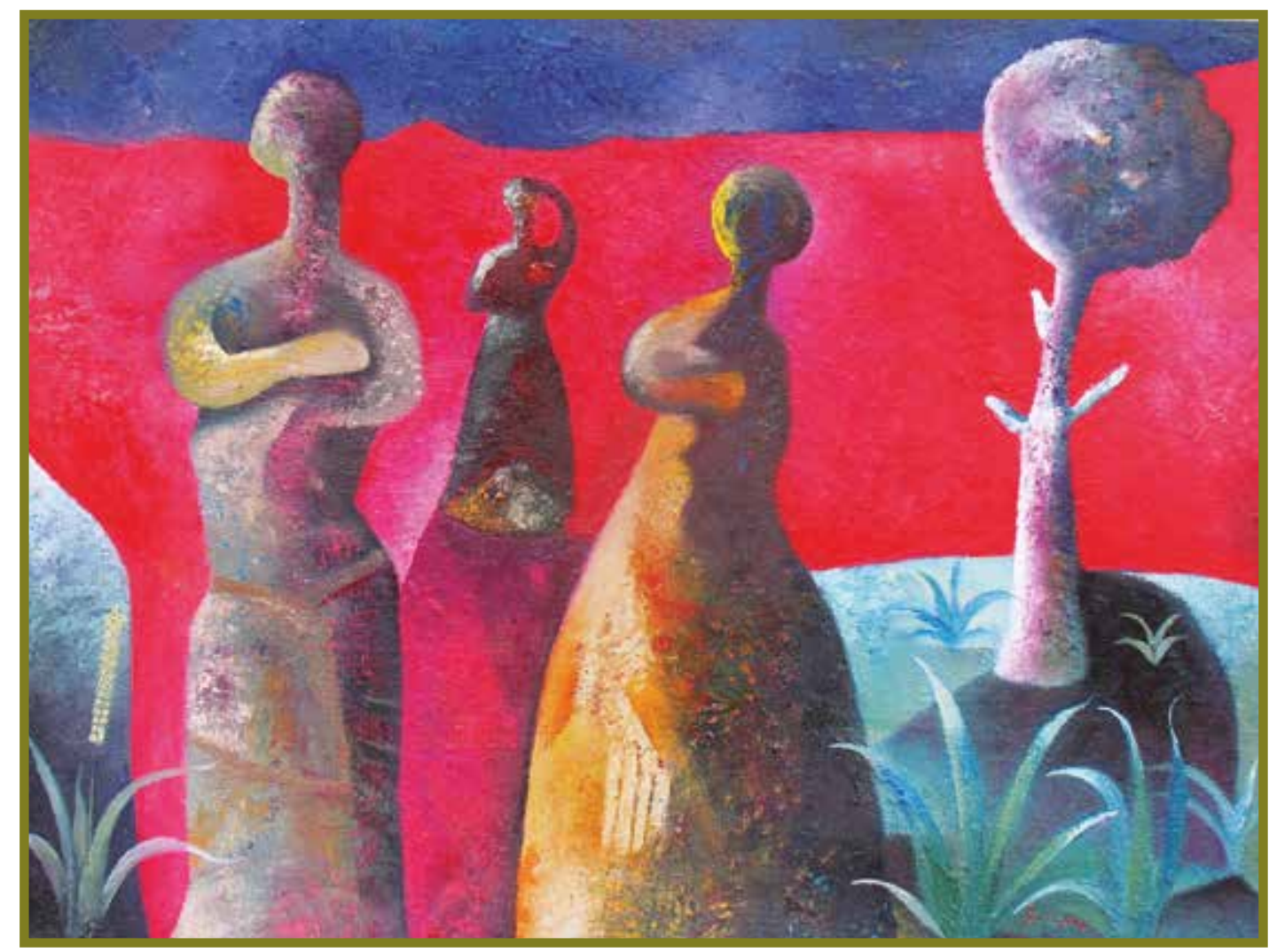

Caminantes. Pintura. Juan Carlos Naañake. 


\section{RESUMEN}

El Perú es un país que goza de una larga tradición minera en América Latina y el mundo. Se le conoce por ser el segundo productor de cobre, plata y zinc a nivel mundial. En América Latina, ocupa el primer lugar en la producción de oro, zinc y plomo. Posee las mayores reservas de plata del mundo y se ubica en tercer lugar en reservas de cobre a nivel mundial, mientras que en Latinoamérica lidera el ranking en reservas de plomo, zinc y molibdeno. Ello refleja el enorme potencial mineralógico que alberga. Es un país bendecido con la existencia de estos recursos naturales y la potestad de su aprovechamiento recae en el Estado, pues fija las condiciones para su aprovechamiento, el mismo que tiene que ser sostenible, y la generación de riquezas proveniente de ese aprovechamiento debe ser repartido de una manera justa y equilibrada a toda la Nación. Sin embargo, nuestro modelo de distribución del canon minero previsto constitucionalmente en el artículo 77, con el reconocimiento del derecho que le asiste a los Gobiernos locales y regionales para recibir una porción de lo recaudado en beneficio de su comunidad, calculado sobre la base de la totalidad de ingresos y rentas provenientes de la explotación de recursos naturales de sus circunscripciones, presenta serias deficiencias, advirtiéndose desigualdad social, corrupción y conflictos sociales. El Congreso de la República aprobó en 2018 la utilización de los recursos del canon para el financiamiento de proyectos de vivienda social; sin embargo, consideramos que si bien es cierto representa avance en la utilización del canon, existen problemas graves que requieren de otras medidas; por ejemplo, vemos un pueblo rico conviviendo al costado de otro pobre en cuyas áreas se realiza actividad minera, visualizando una inequidad en la distribución y utilización del canon minero. ¿Qué hacer? Contestando la interrogante, planteamos la implementación de políticas para la repartición y manejo del canon minero mediante cinco recomendaciones que presentamos al final de este artículo, para su utilización eficiente. No proponemos el ejercicio irrestricto de las prácticas fiscales sino mejoras en su reasignación, división y utilización con la finalidad de mermar la inequidad y desigualdad de los pueblos.

Palabras claves: minería, canon minero, recursos naturales, recaudación, regalias.

\section{ABSTRACT}

Peru is a country that enjoys a long mining tradition in Latin America and the world, it is known for being the second producer of copper, silver and zinc worldwide. In Latin America, it occupies the first place in the production of gold, zinc and lead. It has the largest silver reserves in the world and is in third place in copper reserves worldwide; while in Latin America the rankin leads in reserves of lead, zinc and molybdenum. This reflects the enormous mineralogical potential that it houses, it is a country blessed with the existence of these natural resources and the power of its 
use falls on the State because it sets the conditions for its use the same that has to be sustainable, and the generation of wealth from that use must be distributed in a fair and balanced way to the entire Nation. However, our model of distribution of the mining canon constitutionally provided for in article 77 , with the recognition of the right that assists local and regional governments to receive a portion of the proceeds for the benefit of their community, calculated on the basis of the Total income and income from the exploitation of natural resources of its constituencies, presents serious deficiencies, warning of social inequality, corruption and social conflicts. The Congress of the Republic, approved in 2018, the use of the resources of the canon for the financing of social housing projects; However, we believe that while it is true represents progress in the use of the canon, there are serious problems that require other measures, for example, we see a rich people living side by side with another poor in whose areas mining activity is carried out, visualizing an inequity in the distribution and use of the mining canon. What to do? Answering the question, we propose the implementation of Policies for the distribution and management of the mining canon through five recommendations that we present at the end of this article, for efficient use. We do not propose the unrestricted exercise of fiscal practices but rather improvements in their reallocation, division and use in order to reduce the inequality and inequality of the peoples.

Key words: mining, mining canon, natural resources, collection, royalties. 


\section{NOTAS INTRODUCTORIAS}

El Perú poco a poco fue descubriendo la inmensa cantidad y calidad de recursos naturales que tenemos, especialmente relacionado con la actividad minera, siguiendo las alineaciones en marco de la política del Estado, en su interdependencia con el entorno social, buscando la gestión social-ambiental con excelencia, uso y el manejo responsable de los recursos naturales para impulsar el desarrollo sostenible. ${ }^{1}$

Hay que tener en cuenta que, a nivel internacional, la actividad minera peruana cumple un rol significativo, tomando en consideración que, en términos de valor de producción, ocupa el sexto lugar en el mundo. ${ }^{2}$ Cabe señalar que, si bien la orientación política actual es la de reactivar las inversiones en el sector minero, esta postura se encuentra en contradicción con la percepción social poco favorable sobre los beneficios derivados de la minería en las condiciones de vida e impactos de los agentes involucrados; situación que ha devenido en conflictos sociopolíticos, aunados a los pasivos ambientales generados, principalmente, por la actividad minera ilegal. ${ }^{3}$

Hemos sido testigos del boom de precios de los metales ${ }^{4}$ que impactó positivamente en las utilidades de las empresas mineras que operan en el Perú, lo cual incrementó considerablemente la recaudación por canon y regalías mineras. Ante esto, los gobiernos locales recibieron más de S/. 30000 millones en total. Debido a la magnitud del monto recibido y al hecho de que éste debe ser invertido exclusivamente en infraestructura, el canon y las regalías mineras tiene la obligación de mejorar el bienestar de la población y favorecer el desarrollo económico. No obstante, en la realidad no se ha evidenciado de manera concreta que estas transferencias se hayan usado eficientemente y que hayan tenido un impacto neto positivo.

Anuario Minero 2017, editado por el Ministerio de Energía y Minas. Primera edición. 30 de abril de 2018, 116.

2 Armando Gallegos, Ali Díaz, Andrea Nieto, Minería: retos y posibilidades. Planificación estratégica del sector minero en el Perú y benchmark con seis países mineros (Lima, Instituto de Ingenieros de Minas del Perú, 2017), 16.

3 Isabel Medrano Sánchez y Jessica Obeso Cuadra, La concesión minera: aprovechamiento de recursos minerales, limitaciones legales y propuesta normativa (Lima: Grupo Editorial Lexus\& Iuris, 2018), 25.

4 Período 2005-2014. 
Pero, ¿Por qué no se ha dado el impacto positivo del canon minero en las prácticas fiscales subnacionales en Perú? Si en la práctica no se puede evidenciar si el régimen de distribución de fondos asociados a la actividad minera ha promovido o no la ampliación de brechas en el desarrollo entre regiones al interior del país a través del efecto sobre las decisiones fiscales (ingresos y gastos) de las regiones. Reconocemos el carácter exógeno del canon minero cuya distribución no responde a la aplicación de principios compensatorios sino a la producción minera de las regiones. Por otro lado, el análisis económico indica que las transferencias por canon minero no tienen efecto sobre la recaudación local, pero sí sobre la composición del gasto, incrementando la importancia relativa de la inversión pública.

La inversión pública impulsa las capacidades productivas de los gobiernos locales, principales beneficiarios del canon, y el hecho de que la distribución del canon se concentra en las regiones más ricas, posibilita que el régimen de transferencias contribuya a ampliar las brechas de desarrollo entre las distintas regiones que conforman el Perú.

El actual sistema de transferencias presenta una serie de problemas como la generación de inequidad horizontal y vertical que deberán ser tomados en cuenta por el siguiente Gobierno con el objetivo de reformar del proceso de descentralización. Este es un tema prioritario para el país sobre el que mucho se habla, pero no existe un debate real en torno a las alternativas a implementarse. Uno de los aspectos ineludibles es el canon y sus posibilidades de reforma.

El contexto macroeconómico actual del país no es nada alentador; por un lado, tenemos el panorama de la corrupción que ha conllevado a una especie de incertidumbre y que ha originado la inestabilidad política y económica, falta de inversión, caída de las utilidades de las empresas mineras y paralización de una serie de proyectos mineros. Ante esto, las autoridades regionales y locales siguen con la idea de que recibirán recursos ligados al canon pues lo consideran como una suerte de "derecho adquirido" cuando su naturaleza es transitoria y volátil. La evolución reciente de los precios y los montos transferidos vía canon y regalías han elevado las expectativas que no están siendo satisfechas, lo que genera un mayor nivel de conflictividad e inseguridad.

Pero este tema no se maneja adecuadamente, cuando no solo es responsabilidad de las autoridades subnacionales sino también de los Gobiernos de turno que, al visualizar una bonanza económica proveniente de la explotación de los recursos, realizan una inadecuada gestión cuando aumentan los montos transferidos y al contrario realizan anuncios grandilocuentes de bonanzas generando sobregastos y sobreendeudamientos. Debe tenerse en cuenta que estos incrementos productos de los buenos precios de los metales no dependen de ellos, sino que es producto de un factor totalmente exógeno. Generar expectativas es una mala práctica, los recursos fiscales deben ser administrados sobre bases ciertas y fijas que no dependan de cotizaciones internacionales, y sobre todo deben capacitar a los Gobiernos 
regionales y locales sobre las implicancias de los precios de estos recursos que son de carácter cíclico y temporal.

Es así que, si caen los recursos a ser distribuidos, la acusación recurrente será que el Gobierno Nacional se ha quedado con los recursos fiscales o que los ha administrado mal, sin tomar en cuenta que la verdad es que los ingresos se han reducido motivados por factores externos y por una inadecuada administración estatal. Ante esto, se produce una doble problemática, resolver las expectativas de los Gobiernos subnacionales y la desigualdad fiscal que se genera entre los pueblos que se ubican en los diferentes distritos y provincias del país, pero esto solo es la punta del iceberg, el real problema está orientado al gasto eficiente de estos "pocos" o "muchos" recursos, no es secreto que existe mucha deficiencia al momento de desarrollar proyectos y obras de infraestructura necesarias precisamente para satisfacer las carencias de la población. Esto no es otra cosa que las consecuencias de la corrupción que vivimos, lo que genera y eleva el nivel conflictividad del país pues justo en dichas localidades donde existe actividad minera se evidencia pobreza y ausencia del Estado.

Ante esta situación, de distribución de recursos, vemos a un pueblo rico conviviendo al lado de otro pobre y que tiene actividad minera en su área, por todos lados vemos una inequidad absoluta, ¿Qué hacer? Mejorar en la equidad, distribución de los recursos y políticas de gastos eficaz, para tal efecto, planteamos un modelo de utilización eficiente del canon y regalías mineras. No proponemos el ejercicio irrestricto de las prácticas fiscales sino planteamos recomendaciones que involucran mejoras en la aplicación del canon minero y regalías desde la reasignación de la distribución del mismo, para que se mejore la utilización del canon minero y erradicar la inequidad y desigualdad de los pueblos.

\section{LOS RECURSOS NATURALES}

\subsection{Los recursos naturales y su clasificación en la normativa}

Crepúsculo en la Isla de Pascua corresponde a la segunda parte de la obra Colapso, una investigación realizada por Jared Diamond, quien recibiera los premios Burr de la Sociedad de Geografía Nacional y Pulitzer; allí explica la historia de esta isla y los misterios de las canteras de Rano Raraku que contenía piedras donde labraron gigantescas estatuas; narra la forma de vida de sus tribus, jefes, clanes y aldeanos que corresponde al siglo XVIII donde utilizando su propia fuerza muscular, destruyeron su medio ambiente, agotando sus recursos naturales y con ello desapareció su sociedad, convirtiéndose en la más gigante muestra de destrucción forestal del Pacífico y la más enorme del mundo; mostrándose los resultados de no realizar un uso adecuado y sostenible de los recursos naturales. ${ }^{5}$

5 Colapso, $6^{a}$ edición, España: Liberduplex S. L. U., 115. 
Pero, ¿qué son los recursos naturales?

Se consideran recursos naturales a todo componente de la naturaleza susceptible de ser aprovechado por el ser humano para satisfacción de sus necesidades y que tenga un valor actual o potencial en el mercado. ${ }^{6}$ Los recursos naturales son todo aquello que encontramos en la naturaleza y que el ser humano puede utilizar para beneficiarse económicamente y para satisfacer sus pretensiones, es decir, le saca una utilidad.

Así también, tenemos elementos naturales pero que se diferencian de los recursos naturales, ya que estos últimos constituyen una especie dentro del género de los elementos naturales propuestos a satisfacer las necesidades humanas. En efecto, los elementos naturales son todas las cosas que la naturaleza brinda, independientemente de su utilidad, pues el entorno natural ofrece al hombre un conjunto de elementos de origen animal, vegetal, mineral, químico y energético, que constituye parte del ambiente en que transcurre su existencia.

Es necesario precisar que no todos los elementos son aprovechados por el hombre para el desenvolvimiento de sus actividades, es decir, no todos los elementos naturales satisfacen las necesidades humanas, por lo que no pueden considerarse recursos naturales. Entonces, para que cada uno de los elementos naturales sea considerado recurso natural resulta indispensable el aporte de una utilidad física o estética, actual o potencial, es decir, que la humanidad pueda utilizarlos en su provecho.

En otra acepción dada en el Portal del Ministerio de Agricultura y Riego, consideran recursos naturales a todo componente de la naturaleza que puede ser aprovechado por el ser humano para la satisfacción de sus necesidades y que tenga un valor actual o potencial en el mercado, tales como las aguas superficiales y subterráneas; el suelo, subsuelo y las tierras; la diversidad biológica, como las especies de flora, de la fauna y de microorganismos; los recursos genéticos, y los ecosistemas que dan soporte a la vida; los recursos energéticos: hidrocarburíferos, hidroenergéticos, eólicos, solares, geotérmicos; y la atmósfera, el espectro radioeléctrico; y los minerales, entre otros. ${ }^{7}$

Así también, el Tribunal Constitucional ${ }^{8}$ señala que los recursos naturales son elementos naturales que el ser humano aprovecha para satisfacer sus necesidades materiales o espirituales; vale decir, que gozan de aptitud para generar algún tipo de provecho y bienestar.

6 Artículo 3 de la Ley N² 26821 - Ley Orgánica para el aprovechamiento sostenible de los recursos naturales. Acceso el 18 de agosto, http://www.ana.gob.pe/media/95192/ley_26821.pdf

7 Ministerio de Agricultura, Portal del MINAGRI, acceso 15 de agosto del 2018, http://www.minagri.gob.pe/portal/41-sector-agrario/recursos-naturales/314-introduccion

8 En la Sentencia del Tribunal Constitucional recaída en el expediente Nº48-2004-PI/TC, 11. 
Carlos Westreicher ${ }^{9}$ señala que los recursos naturales son aquella parte de la naturaleza que tiene alguna utilidad actual o potencial para el hombre, es decir, son los elementos naturales que el ser humano aprovecha para satisfacer sus necesidades materiales o espirituales.

Para la Organización de las Naciones Unidas (ONU), recursos naturales se resume claramente como: "Recursos naturales son todos aquellos recursos que el hombre encuentra en su ambiente y que puede utilizar en su beneficio". ${ }^{10}$ les:

Conforme a lo anterior, se pueden establecer tres características sobre los recursos natura-

a) Son proporcionados por la naturaleza, en oposición a los denominados recursos culturales: de creación humana;

b) Son capaces de satisfacer las necesidades humanas, esto es, de ser útiles para el hombre;

c) Su apropiación y transformación dependen del conocimiento científico y tecnológico, a lo que deben añadirse las posibilidades económicas del Estado en que se encuentra ubicados. ${ }^{11}$

Existen diversas clasificaciones de los recursos naturales bajo criterios como según su utilidad, según su naturaleza, según su tasa de renovación, según el sistema de procedencia, entre otros. Para efectos de esta investigación considerar la clasificación según su tasa de renovación.

Nuestro ordenamiento jurídico clasifica a los recursos naturales en renovables y recursos naturales no renovables, efectuándose esta distinción en función a la tasa de generación o regeneración y cantidad de consumo de ellos. ${ }^{12}$

Los recursos renovables son aquellos recursos cuya existencia no se agota con su utilización, debido a que vuelven a su estado original o se regeneran a una tasa mayor a la tasa con que los recursos renovables son disminuidos mediante su utilización. Esto significa que ciertos recursos renovables pueden dejar de serlo si su tasa de utilización es tan alta que evite su renovación. ${ }^{13}$

9 Carlos Andaluz Westreicher, Manual de derecho ambiental. 1ª. edición (Proterra, 2006), 4.

10 Naciones Unidas, Recursos naturales de los países en desarrollo, investigación, explotación y utilización racional (Departamento de Asuntos Económicos y Sociales, 1970), 5.

11 La Constitución comentada. Tomo II. Segunda Edición (Lima: Gaceta Jurídica, 2013), 170.

12 El artículo 66 de la Constitución Política del Perú de 1993 reconoce a los recursos renovables y no renovables, considerando su capacidad de regeneración o resiliencia, 21-22.

13 "Recursos Renovables", Zona Económica, acceso 16 de agosto del 2018, http://www.zonaeconomica.com/recursos-renovables 
También se denominan a aquellos recursos naturales que a pesar de ser utilizados se restauran y pueden nuevamente ser aprovechados; pero la problemática se suscita cuando estos recursos siendo renovables dejan de serlo por su alta utilización que no permite su renovación; el uso irracional no consiente su desarrollo sostenible.

El Tribunal Constitucional refiere que son recursos renovables aquellos que, a pesar de ser utilizados, pueden regenerarse y, por ende, no perecen para su posterior aprovechamiento. En tal sentido, devienen en duraderos y obtienen permanencia de utilidad.

Esta capacidad de autorregeneración y autodepuración se denominan resiliencia y solo tienen lugar cuando el ser humano no excede la capacidad de carga en su aprovechamiento. Por tal motivo, un recurso será renovable en la medida que su utilización o aprovechamiento no se realice de manera desmesurada e irracional. Solo así se podrá alcanzar el aprovechamiento sostenible del bien ambiental. ${ }^{14}$

Nuestro Código Civil en sus artículos 890 y 891 se aproxima a una definición jurídica sobre los recursos renovables o no agotables, al señalar que son frutos, los provechos renovables que produce un bien, sin que se altere ni disminuya su sustancia y para tal efecto, identifica como frutos naturales, los que provienen de un bien, sin intervención humana.

También los llaman "recursos no agotables".

Los recursos no renovables, son aquellos recursos naturales que existen en cantidades predeterminadas, debido a que la naturaleza no los restaura en cortos espacios de tiempos.

Los no renovables corresponden a aquellos que no pueden ser restablecidos en un tiempo menor al de su consumo; son recursos agotados más vertiginosamente de lo que la naturaleza pueda reponerlos. Por ejemplo, el petróleo, los minerales metálicos y no metálicos, el gas natural.

Estos recursos son aquellas cuya primera explotación ocasiona el agotamiento del recurso llevando a la extinción de la fuente productora. El Tribunal Constitucional, indica que son aquellos que, al ser utilizados, se agotan irremediablemente. Su utilización o provecho comporta inexorablemente la extinción de su fuente productiva, habida cuenta de su incapacidad de alcanzar autorregeneración o autodepuración. ${ }^{15}$

También los llaman "recursos agotables".

14 Sentencia del Tribunal Constitucional recaída en el Expediente $N^{\circ}$ 0048-2004-PI/TC, p. 13

15 Sentencia del Tribunal Constitucional recaída en el Expediente $N^{\circ}$ 0048-2004-PI/TC, 13. 


\subsection{Los recursos naturales en la Constitución Política del Perú de 1993}

La Constitución Política del Perú del 1993 no contiene definición de recursos naturales; esto se debió haber efectuado y así poder determinar cuáles son los recursos que se encuentran comprendidos dentro de dicha definición; la referencia que efectúa es su clasificación de acuerdo a las categorías de renovables y no renovables; así tenemos que el artículo 66 de la Constitución señala que "los recursos naturales, renovables y no renovables, son patrimonio de la Nación. El Estado es soberano en su aprovechamiento. Por ley orgánica se fijan las condiciones de su utilización y de otorgamiento a particulares. La concesión otorga a su titular un derecho real, sujeto a dicha norma legal”.

Aparte de su clasificación, conforme lo dispone el primer párrafo del mencionado artículo, todos estos recursos son patrimonio de la nación, vinculándolos de esta manera al interés nacional y al bienestar de toda la población, separándolos de intereses privados y egoismos particulares, sean nacionales o extranjeros.

Es necesario mencionar que Estado y Nación son conceptos distintos, donde el Estado representa la organización política de la Nación y la Nación es una sociedad natural de hombres a los que la unidad de territorio, de origen, de costumbres y de idiomas, conduce a una comunidad de vida y de conciencia social, por ello, se dice que la nación es el elemento humano del Estado, integrado por un grupo de personas con identidades históricas, culturales, sociales y materiales.

Asimismo, el artículo bajo comentario señala que los recursos naturales son patrimonio de la nación, lo que significa que constituyen el patrimonio de los pueblos, su riqueza y su herencia, y de ellos depende el bienestar, más que de cualquier otro factor, y así lo han comprendido los hombres desde la más remota antiguedad al luchar y morir por ellos. ${ }^{16}$

Vale decir tambien que los recursos naturales pertenecen a todos los peruanos, no al propietario del terreno donde se encuentre ubicado un yacimiento minero, no a un grupo de personas, sino a todos los pobladores del país.

Cuando nos referimos a que el Estado es soberano en su aprovechamiento, significa que los recursos naturales se encuentran sometidos a la soberanía permanente del Estado, refiriéndonos en todo momento a la potestad que tiene para decidir cómo, quién y las condiciones bajo las cuales pueden aprovecharse dichos recursos; no obstante, esta soberanía está anexa a obligaciones como la de maximizar los beneficios producto de la explotación, desarrollar programas en beneficio de las poblaciones aledańas y sobre todo el deber de salvaguardar el uso sostenible de estos.

16 Marc J. Dourojeam, "Recursos naturales, desarrollo y conservación en el Perú”, en La Constitución comentada. Tomo II (Lima: Gaceta Jurídica), 171-172. 
La soberanía que se atribuye al Estado según la definición vigente debe interpretarse como la autoridad suprema del poder público sobre estos recursos, conforme al segundo alcance del vocablo contenido en el Diccionario de la Real Academia Española. En este punto, resulta saludable mencionar, como ya hemos visto, que los recursos naturales por un lado constituyen parte del patrimonio de la nación y por otro es el Estado quien ostenta el dominio y ejerce la soberanía sobre ellos. ${ }^{17}$

No puede haber propiedad privada sobre los recursos naturales, cuando se ha demostrado en diversas oportunidades que las características de la propiedad privada son mas eficientes que la propiedad estatal, pues al integrar el patrimonio de la Nación le pertenecen a esta y por lo tanto a todos sus habitantes colectivamente considerados; pero en lo que refiere a su aprovechamiento, quien es soberano en establecer las reglas es el Estado.

Respecto de la condición de soberanía sobre los recursos naturales, la Constitución le reconoce al Estado, pues su contenido está más acorde con los atributos que debe ostentar el Estado sobre ellos, superando las definiciones pasadas de pertenencia, entendida como propiedad, del Estado sobre esos recursos, ${ }^{18}$ que podía prestarse a interpretaciones equívocas sobre el alcance del concepto.

Asimismo, el artículo 66 de la Constitución define que los recursos naturales son patrimonio de la nación y que el Estado es soberano en su aprovechamiento. Esta definición encierra una aparente paradoja, pues identifica a dos sujetos como ejerciendo títulos o atributos sobre una misma clase de bienes.

¿Puede jurídicamente sostenerse que la nación, concepto principalmente sociológico e histórico resulte titular de un patrimonio, concepto jurídico y económico? Pudo haberse prescindido perfectamente de la mención al patrimonio de la nación sobre los recursos naturales, pues no es una definición con contenido jurídico, que más bien induce a situaciones confusas de interpretación, cuando no a la creación de expectativas patrimoniales colectivas, en un tema en el que debe guardarse mucha objetividad y mesura.

\subsection{Presencia de recursos naturales en el Perú}

Los recursos naturales proveen de materias primas esenciales para la modernidad y pueden ser transformadas, lo que les da mayor valor. Son una fuente importante de creación de riqueza y tienen relevancia en la economía de cada país.

17 El ejercicio de esta soberanía constituye un claro ejemplo del Ius Imperium del Estado respecto a la explotación de los recursos naturales de la Nación. El artículo 67 también refleja lo mencionado al señalar que "el Estado determina la política nacional del ambiente. Promueve el uso sostenible de sus recursos naturales". Del mismo modo, a través del artículo 19 de la Constitución se determina que los derechos para el aprovechamiento de los recursos naturales se otorgan a los particulares mediante las modalidades que se establecen en las leyes especiales para cada recurso natural, 136.

18 Enrique Lastres, "Los recursos naturales en la Constitución vigente", Ius et Veritas. Revista editada por estudiantes de la Facultad de Derecho de la Pontificia Universidad Católica del Perú, n. 9 (Año V): 139-140. 
Sin embargo, los Estados enfrentan diversas problemáticas en torno no solo a la explotación de los recursos naturales mineros, sino en torno a la distribución del canon y regalías que son recursos públicos ya captados, de acuerdo a lo estipulado en el Art. 9 de la Ley No 27506, donde se contempla la constitución del Canon Minero, aumentándose la participación de $20 \%$ a $50 \%$ del impuesto a la renta, determinándose la intangibilidad del canon minero en relación a los beneficios tributarios. Donde a la letra se indica: "El canon minero está constituido por el $50 \%$ (cincuenta por ciento) del total de los Ingresos y Rentas que pagan los titulares de la actividad minera por el aprovechamiento de los recursos minerales, monto que no podrá ser afectado por los beneficios e incentivos tributarios que recaigan sobre el Impuesto a la Renta”.

Es así que, de acuerdo a la normativa actual del canon, tanto las regiones como las municipalidades provinciales y distritales tienen restricciones para disponer de los ingresos provenientes por dicho concepto, en razón a que pasan filtros para la aprobación de sus proyectos, y si no logran la aprobación hasta finalizado el ejercicio anual estos no pueden ejecutarse, en consecuencia, el dinero proveniente del canon ya no lo deben utilizar, es decir, tienen dinero en las arcas, pero no lo pueden gastar, lo que constituye una limitación para estas entidades, pero ¿este escenario que refleja ante la población? Que en una zona donde existe actividad minera no se visualiza progreso y directamente señalan a la empresa minera como responsable de tal situación, generándose conflictos, cuando realmente tenemos aún grandes deficiencias que salvar; lo que hace ineludible la implementación de políticas para la adecuada aplicación del canon y regalías mineras. Siendo necesario también la creación de un fondo subnacional que opere en las regiones y municipalidades para ser utilizado cuando se requiera acrecentar el gasto público ante una recesión.

De otro lado, hemos podido apreciar que se han ejecutado obras sin sensatez; allí donde faltan líneas básicas esenciales como agua, desagüe, luz, se efectúa un coliseo. ¿Puede ello ser lógico? Nuestra respuesta recae en un No por sí sola. Y, jes necesario que exista un ente independiente que supervise, fiscalice y sancione a quienes realizan una deficiente labor? La respuesta a la que arribamos es un Sí.

Es precisa la implementación de políticas públicas referidas al canon y regalías mineras, considerando que el Perú es uno de los países que goza de una larga tradición minera en América Latina y el mundo. Es el segundo productor de cobre, plata y zinc a nivel mundial. En América Latina, ocupa el primer lugar en la producción de oro, zinc y plomo. Asimismo, posee las mayores reservas de plata del mundo y se ubica en tercer lugar en reservas de cobre a nivel mundial; mientras que en Latinoamérica lidera el ranking en reservas de plomo, zinc y molibdeno. Ello no solo refleja el enorme potencial que posee el Perú en recursos minerales, sino además la capacidad de producción de la minería peruana y la estabilidad de sus políticas económicas. ${ }^{19}$

19 Anuario Minero 2017, editado por el Ministerio de Energía y Minas, primera edición, 30 de abril de 2018, 15. 
Si sigue aumentando su producción minera, el Perú se podría ubicar entre los cinco primeros países del mundo productores de recursos minerales. Sin duda existen minerales y su potencia minera traspasa fronteras, de allí la importancia de la riqueza mineral en su desarrollo industrial y comercial, el mismo que es reconocido a nivel internacional, y que sea considerado un destino atractivo para inversiones.

Como hemos señalado, el Perú se ubica entre los principales países productores de minerales del mundo y su tradición minera ha pasado a convertirse en una pieza clave de su desarrollo económico logrando convertirlo en un país bendecido por la existencia de sus recursos. Esta bendición tiene importante reputación en el contexto internacional, en gran medida como señala Elva Arias, porque "como país (...) tenemos una canasta polimetálica" ${ }^{20}$

En efecto la diversidad de sus recursos minerales, metálicos y no metálicos, hidrocarburos, gas naturales y energía, sin mencionar su biodiversidad en flora y fauna lo hace un país completo en lo que a recursos naturales renovables y no renovables se refiere.

En reporte transmitido por la BBC de Londres con el título de "Perú es el país con mayor potencial minero en el mundo", que tiene como fuente de información un vasto trabajo de geología económica-minera desarrollado por el Servicio Geológico Minero de Argentina SEGEMAR, institución equivalente a lo que en nuestro país es el INGEMMET, se afirma que el Perú es el país con mayor potencial minero en el mundo, empatando el primer lugar con Rusia. Posee las más grandes reservas de minerales conocidas de América Latina, donde se producen hasta cuarenta tipos de metales. La información añade que el estudio de SEGEMAR considera exclusivamente las condiciones geológicas y las reservas probadas y probables de diferentes minerales con contenidos de metales base, metales preciosos, minerales energéticos e industriales en general. ${ }^{21}$

El potencial geológico existente en el territorio peruano, la calidad y diversidad de sus recursos minerales sumado a la implementación de políticas estratégicas por parte del Estado no debe ser solo para atraer grandes inversiones, sino que para efectuar la correcta y adecuada distribución y utilización del canon y regalías mineras con lo cual se evitaría esa mala imagen que recae en el empresariado minero, minimizándose conflictos.

\subsection{Uso sostenible de los recursos naturales}

El artículo $28^{\circ}$ de la Ley 26821, Ley Orgánica para el Aprovechamiento Sostenible de los Recursos Naturales, establece que el aprovechamiento sostenible implica el manejo racional

20 Elva Arias, "Las mesas de desarrollo son una buena iniciativa del gobierno", Horizonte Minero. Revista Internacional de Minería y Energía, n. 91 (Año 14, setiembre 2013): 36

21 Lino Aranzamendi y Julio Huamán, Mineria: potencialidad, problemática, derecho y legislación (Lima, Perú: Editora Jurídica Grijley, 2015), 47. 
de los recursos naturales teniendo en cuenta su capacidad de renovación, evitando su sobreexplotación y reponiéndolos cualitativa y cuantitativamente, de ser el caso.

Al referirnos al aprovechamiento sostenible de los recursos naturales no renovables, el mismo artículo $28^{\circ}$ intenta una definición que resulta muy poco precisa y bastante confusa al señalar que este aprovechamiento consiste en la explotación eficiente de los mismos "bajo el principio de sustitución de valores o beneficios reales, evitando o mitigando el impacto negativo sobre otros recursos del entorno y del ambiente".

No obstante, resulta preciso reconocer que el concepto de sostenibilidad ${ }^{22}$ se entiende tambien como aquel que es capaz de integrar las variables de crecimiento económico, protección ambiental y equidad o justicia social, por lo que el desarrollo de una actividad de aprovechamiento de recursos naturales renovables y/o no renovables debe tener en cuenta estos elementos y su integración, donde la participacion de las poblaciones locales y su identificacion con el proyecto cobran un peso estrategico.

El concepto de uso sostenible de los recursos naturales involucra su manejo sostenible, mediante actividades de caracterizacion, evaluación, planificación, aprovechamiento, regeneración, reposición, protección y control conducentes a asegurar la produccion sostenible y la conservación de la diversidad biológica, los recursos naturales y el ambiente.

La sostenibilidad requiere de una relación equilibrada entre las necesidades humanas y el tamańo limitado y la capacidad finita de recursos de la tierra. El bienestar humano debe buscarse dentro de la capacidad del medio ambiente natural para tolerar, sostener y absorber tal uso, cuyos niveles actuales son excesivos y no sostenibles. Por lo tanto, son necesarias acciones correctivas urgentes. La idea de sostenibilidad tiene tres componentes claves: el medio ambiente, el crecimiento económico y el bienestar humano. El desarrollo sostenible resalta la relación entre las necesidades humanas (presentes y futuras, de ricos y pobres) y la capacidad de la naturaleza para satisfacer esas necesidades. El uso sostenible de recursos es el método o proceso mediante el cual el concepto de desarrollo sostenible es aplicado al uso de los recursos naturales, tanto renovables como no renovables. El proceso no trata del uso de recursos específicos aisladamente, se requiere un enfoque integrado, en el que el uso sostenible de recursos sea definido como "el uso de los recursos naturales que permanece siempre dentro de los límites de la capacidad ambiental y sobre esa base satisface las necesidades de la presente generación, particularmente las de los pobres, sin comprometer la capacidad de las generaciones futuras para satisfacer sus propias necesidades".

22 El concepto de sostenibilidad o uso sostenible generalmente aceptado se refiere al aprovechamiento de los recursos naturales en tal forma y magnitud que no afecte su capacidad de regeneración y que permita satisfacer las necesidades de las presentes y futuras generaciones. Comisión Brundtland. 
Es importante la relación de la población y el medio ambiente a través de tres perspectivas: el uso y la conservación de los recursos naturales, los problemas ambientales en el mundo y el desarrollo sostenible. ${ }^{23}$

Pero el problema no es solo el uso sostenible de los recursos naturales y su explotación, sino también los ingresos que provienen de él por efectos del canon minero y regalías versus su utilización, teniendo en consideración que tanto el canon minero y canon petrolero son los únicos ingresos descentralizados en función a que los Gobiernos Regionales, Municipalidades Provinciales y Distritales son los mismos receptores de dichos ingresos y disponen el gasto en ejecución de obras pero en muchos casos revierte el dinero al Estado porque no lograron la aprobación de dichos proyectos.

En este escenario, la importancia de políticas genuinas de manejo del canon minero es de necesidad urgente por su envergadura y efectos, siendo real, pero resultando absurdo admitir polos de riqueza para las empresas mineras y la contraparte, la población envuelta en círculos de miseria. Lo cual no es responsabilidad de las empresas mineras, como le atribuye la población, sino del inadecuado manejo de estas partidas económicas, toda vez que el dinero proveniente del canon existe, pero en muchos casos sin poder usarse por una restricción legal y por falta de eficiencia de los organismos del Estado. En esta línea de ideas deberían replantearse nuevas alternativas para corregir estas deficiencias y crearse una entidad estatal con autonomía para supervisar, fiscalizar y sancionar, si fuera el caso, su utilización; debido a que su contribución debe representar un círculo de crecimiento y desarrollo.

\section{LA ACTIVIDAD MINERA}

Referirnos al canon y regalías mineras implica necesariamente tratar del sector minero, columna vertebral de nuestra economía nacional. Como país minero, somos testigos de lo importante que es este sector. En el Perú, la minería ha sido siempre una actividad productiva ligada a la historia económica, social y cultural de los pueblos. Como vemos, la minería forma parte de la evolución y del progreso de la humanidad, sus orígenes se diluyen en los más remotos tiempos de las culturas prehistóricas y nuestra cultura está íntimamente ligada a la explotación de los recursos.

La actividad minera está vinculada directamente al uso y consumo de bienes y servicios que hacemos los humanos en el diario vivir, y por ello, están mediados principalmente por algunos factores como la demografía y la geografía, definida como la relación entre la cantidad

23 "El uso sostenible de los recursos naturales", Guía metodológica: el desarrollo sostenible y el ordenamiento territorial. Proyecto, ordenamiento participativo del territorio y de los recursos naturales en los Andes peruanos. Módulo II, acceso el 18 de agosto del 2018, http://ongadg.be/bibliadg/bibliotheque/opac_css/doc_num/fiches_techniques/guia_del_facilitador_modulo_2.pdf 
de humanos y el territorio que ellos habitan, el desarrollo económico de los territorios, que incentiva fenómenos como los desarrollos en construcción e infraestructura y la urbanización y los cambios en la capacidad adquisitiva de las personas, que cambian patrones de consumo y demandas de productos tecnológicos.

De esta forma, la actividad económica minera prácticamente está vinculada al desarrollo de las sociedades y hace parte fundamental de lo que necesitan las naciones para su presente y su futuro, dado que el panorama mundial de demanda de minerales continuará en ascenso por el desarrollo económico de algunas naciones y el crecimiento demográfico de otras, las empresas mineras se están enfocando en desarrollar proyectos en diferentes regiones antes no explotadas, como Latinoamérica; pero no se puede hacer un manejo indiscriminado como el de décadas anteriores: la reposición de reservas es más difícil por restricciones ambientales que son más duras a nivel mundial y en las operaciones modernas es una premisa el disminuir el impacto ambiental negativo ocasionado por la actividad minera.

Está claro que no podemos renunciar a esta actividad importante, pero también debemos reconocer que la minería ya no se realiza de cualquier forma, sino que para su desarrollo se debe respetar elementos sociales, culturales y sobre todo ambientales pues cada uno de estos elementos cumplen un papel preponderante en todos y cada uno de los proyectos de inversión minera, pues implementarlos implica que su aporte conlleve realmente al desarrollo sostenible de los pueblos.

Así también, la minería juega un papel importante en la economía peruana a través de la generación de valor agregado, divisas, impuestos, inversión y empleo. A nivel departamental, la importancia de la minería se hace evidente por su participación en la actividad económica, la transferencia de canon minero y la promoción de recursos para el desarrollo a través del aporte directo de recursos. A nivel nacional, en un contexto de altos precios internacionales de los minerales, la minería ha experimentado un importante dinamismo que se reflejó en la provisión de divisas a la economía, la generación de ingresos fiscales por impuestos y regalías mineras, la creación de empleos directos e indirectos, y el incremento del crecimiento potencial de la economía.

El principal impacto generado por la actividad minera en el nivel de vida de las personas es el aumento en el ingreso de las familias asentadas en las localidades donde se desarrolla dicha actividad. Este aumento, además, se produce junto con la dinamización de los mercados laborales locales sin un efecto negativo sobre la actividad agrícola.

De acuerdo a los resultados analizados, no hay una pérdida en los ingresos agrícolas en las localidades mineras. Se observa también una reducción de los niveles de pobreza y pobreza extrema (dependiendo del modelo analizado) asociado a la actividad minera y mayores índices de desarrollo humano. Estos resultados son claramente mayores en el caso de la gran minería. 
A pesar de los logros objetivos en términos de ingreso y otros casos puntuales en educación, salud e infraestructura social, la percepción de bienestar de la población parece no reaccionar. Así, cuando se le pregunta a la población sobre su sensación de pobreza y sobre si vive adecuadamente, las respuestas no difieren entre los que viven en zonas mineras y las que no tienen esta actividad.

Este resultado posiblemente este influido por la manera en la que se distribuyen los ingresos provenientes de esta actividad. Posiblemente la regresividad de la distribución de estos ingresos esté influyendo la manera en que estos se perciben, situación que abre una ventana al análisis legal de la distribución de estos ingresos y cuáles son las deficiencias y fortalezas de esta actividad estatal de distribución del canon minero.

Conforme a lo expuesto, el Gobierno Nacional destina recursos hacia los Gobiernos regionales y locales, siendo que gran parte de estos provienen de la actividad minera que se desarrolla en varias de las regiones de Perú.

\subsection{Inversión minera}

El Perú es un país que goza de una larga tradición minera en América Latina y el mundo, donde se le conoce por ser el segundo productor de cobre, plata y zinc a nivel mundial. En América Latina, ocupa el primer lugar en la producción de oro, zinc y plomo. Asimismo, posee las mayores reservas de plata del mundo y se ubica en tercer lugar en reservas de cobre a nivel mundial; mientras que en Latinoamérica lidera el ranking en reservas de plomo, zinc y molibdeno. Ello no solo refleja el enorme potencial mineralógico que posee el Perú, sino además se le reconoce su capacidad de producción y la estabilidad de sus políticas económicas, pues reconoce que es un sector importante para elevar el desarrollo de la población.

A pesar de la crisis política por la que atraviesa nuestro país, se denota la viabilidad de sus políticas de promoción minera que tienen como objetivo reactivar las inversiones en el sector; a través del desarrollo de proyectos de exploración, así como la ejecución de los proyectos de construcción de mina.

Así también, tenemos que entre las ventajas competitivas que ofrece el Perú para invertir en el subsector minero, están los bajos costos de operación y energía, la estabilidad macroeconómica, el nivel de innovación de sus proveedores locales y los esfuerzos que viene realizando el Gobierno peruano para promover una convergencia entre los sectores productivos, las comunidades y la minería; además de su enorme potencial geológico-minero reconocido internacionalmente.

Otro factor importante en destacar es el modelo económico peruano que brinda un marco normativo que establece un trato igualitario a los inversionistas, sin importar su procedencia, así como oportunidades en todas las actividades productivas y de servicios, en el marco de 
una política de libre mercado. Al respecto, el Perú cuenta con un sólido paquete de garantías e incentivos para la inversión privada, a fin de que quienes estén interesados en hacer negocios en el país se sientan seguros, promoviendo que sus actividades se desarrollen con responsabilidad social y cuidado al ambiente. Esto forma parte de un cambio cualitativo del país que tiene como uno de sus pilares más importantes la producción minera. La minería no es una actividad de corto plazo, es una actividad compleja y planificada; transversal, que genera demanda y que anima, de este modo, la productividad de otros sectores incrementando la competitividad general de toda la nación.

La minería, además, es una actividad compleja, dinámica y multidisciplinaria que requiere de inversiones millonarias, levanta infraestructura industrial, habilita accesos y desarrolla redes de comunicación generando focos de desarrollo desde sus primeras fases y no descarta el trabajo arduo que se realiza con las poblaciones con la finalidad de obtener la licencia social. Es imprescindible asociar a la minería con el desarrollo y la transformación, que implican progreso y bienestar. La minería responsable brinda empleo (directo e indirecto) a casi 1,4 millones de personas, siendo que, si se suma a esta cifra a las personas que dependen de estos trabajadores, entonces, la sexta parte de la población encuentra su sustento diario en este importante subsector.

\subsection{Estratos de la minería}

La actividad minera tiene distintos estratos de operación: gran minería, mediana minería, pequeña minería y minería artesanal. ${ }^{24}$ Clasificada según diversos aspectos tales como por tipo de actividad, por naturaleza de las sustancias, por método de explotación, por la forma del yacimiento, por la ubicación del mineral, entre otras.

La gran y mediana minería son promovidas y reguladas por el Ministerio de Energía y Minas; además, la fiscalización ambiental de ambas está a cargo del Organismo de Evaluación y Fiscalización Ambiental, que es una organización pública técnica especializada, adscrita al Ministerio del Ambiente. La pequeña minería y la minería artesanal son reguladas y fiscalizadas ambientalmente por los Gobiernos regionales.

La actividad minera formal es desarrollada por empresas de capitales extranjeros y nacionales. La regulación ambiental y social del sector minero es amplia y especializada. Precisamente, esta especialización se manifiesta a lo largo de la evolución de la fiscalización ambiental de la actividad minera, la cual ha pasado por un proceso de desarrollo institucional iniciado con la Dirección General de Minería del MINEM, seguido por el OSINERGMIN y consolidado

24 Organismo Supervisor de la Inversión en Energía y Minería - OSINERGMIN, “¿Cómo se clasifica la actividad minera en el Perú?”, acceso el 18 de agosto del 2018, http://www.osinergmin.gob.pe/mineria/actividad_minera/clasificacion-minera-peru 
en el 2008 con la creación del MINAM, en la cual está comprendida el OEFA, organismo especializado que asume las funciones de supervisión, fiscalización, sanción y aplicación de incentivos de las actividades mineras.

Uno de los problemas de los estratos de la pequeña minería y la minería artesanal es precisamente el desarrollo de las actividades informales e ilegales impulsadas por los altos precios alcanzados por los minerales en los últimos ańos. De esta manera, el Estado ante este problema, ha motivado que desde el 2010 impulse activamente un programa de formalización de la pequeña minería y de la minería artesanal, así como de erradicación de la minería ilegal. ${ }^{25}$

\subsection{Promoción de la inversión minera}

\subsubsection{Contratos de estabilidad tributaria}

Como parte de las garantías y medidas de promoción a la inversión en nuestro país, las empresas pueden celebrar convenios de estabilidad jurídica con el Estado peruano a fin de mantener la vigencia de determinado régimen normativo por el tiempo que se pacte en el convenio, de acuerdo con los requisitos y condiciones previstas por la normativa sobre la materia. Estos convenios brindan seguridad y predictibilidad frente a posibles cambios normativos que incluyen modificaciones tributarias, administrativas o de otra índole.

Estos convenios constituyen una garantía para los inversionistas frente a los riesgos asociados a cambios en la estructura impositiva del país, estableciéndose que el régimen tributario se mantenga inalterable durante el plazo de vigencia del contrato. Ello, además, resulta relevante para la industria minera que se caracteriza por ser intensiva en capital y cuyos proyectos son de largo plazo. El artículo $1^{\circ}$ del Reglamento del Título Noveno de la Ley General de Minería, referido a las Garantías y Medidas de Promoción a la Inversión en la actividad minera, aprobado por Decreto Supremo No 024-93-EM, señala que la estabilidad tributaria, cambiaria y administrativa son garantías de seguridad jurídica que se conceden a los titulares de la actividad minera para el ejercicio de sus actividades.

De esta manera, el goce del beneficio de la estabilidad tributaria, cambiaria y administrativa se garantiza a través de la suscripción del respectivo contrato con el Estado Peruano, por un plazo que se rige bajo las siguientes condiciones o requisitos:

a) 10 años, para una inversión mínima de US\$20 millones destinada a nuevas operaciones u operaciones ya existentes;

25 El Plan Nacional de Formalización de la Minería Artesanal fue elaborado con los aportes de los integrantes de la Comisión Técnica Multisectorial (CTM), creada por la Presidencia del Consejo de Ministros (PCM) mediante D. S. 0452010-PCM el 8 de abril de 2010 y aprobada mediante D. S. 013-2011-EM, publicado el 30 de marzo de 2011, 2-112. 
b) 12 años, para una inversión de US\$ 100 millones para el inicio de operaciones o US\$ 250 millones para operaciones en marcha; $y$,

c) 15 años, para una inversión mínima de US\$500 millones destinados al inicio de nuevas operaciones $\mathrm{u}$ operaciones ya existentes. ${ }^{26}$

\subsubsection{Devolución definitiva del IGV}

La Ley N² 27623, Ley que dispone la Devolución del Impuesto General a las Ventas (IGV) e Impuesto de Promoción Municipal (IPM) a los titulares de la actividad minera durante la Fase de Exploración y su Reglamento, aprobado por Decreto Supremo N ${ }^{\circ}$ 082-2002-EF, tienen por finalidad brindar incentivos para la ejecución de proyectos de exploración minera a través del otorgamiento de beneficios tributarios a los titulares mineros.

La norma bajo comentario establece, entre otros, los siguientes lineamientos:

- Los titulares de concesiones mineras tendrán derecho a la devolución definitiva del IGV e IPM para la ejecución de sus actividades durante la fase de exploración.

- Los titulares de concesiones mineras deberán cumplir con celebrar un Contrato de Inversión en Exploración con el Estado, que será suscrito por la Dirección General de Minería del Ministerio de Energía y Minas (aprobado por resolución ministerial).

- El Estado garantizará al titular minero la estabilidad de este régimen de devolución.

- La devolución comprende a todas las importaciones o adquisiciones de bienes, prestación o utilización de servicios y contratos de construcción.

Por su parte, el reglamento señala que la devolución definitiva se realizará mediante notas de crédito negociables, del impuesto que haya sido trasladado o pagado en las operaciones de importación y/o adquisición local de bienes, prestación o utilización de servicios y contratos de construcción que se utilicen directamente en la ejecución de las actividades de exploración minera.

Además, establece que el monto mínimo que deberá acumularse para solicitar la devolución será de cuatro (4) UIT y que la devolución definitiva no está condicionada al hecho de que el titular de la concesión minera inicie operaciones productivas. Actualmente, mediante Ley $\mathrm{N}^{\circ} 30404$, se amplió la vigencia de los beneficios y exoneraciones tributarias hasta el 31 de diciembre del 2018. Desde la promulgación de la Ley Nº 27623 y su reglamento, el Ministerio de Energía y Minas (MINEM) a través de la Dirección General de Minería ha suscrito doscientos cinco (205) Contratos de Inversión en Exploración para efectos de Devolución del IGV e IPM, de los cuales setenta y siete (77) han solicitado la devolución del IGV e IPM, representando el $37,56 \%$ de total de contratos suscritos.

26 Anuario Minero 2017, editado por el Ministerio de Energía y Minas, primera edición 30 de abril de 2018, 31. 


\subsubsection{Recuperación anticipada del IGV}

El Decreto Legislativo № 973, que establece el Régimen Especial de Recuperación Anticipada del Impuesto General a las Ventas (IGV) durante la etapa preproductiva y su Reglamento, aprobado por Decreto Supremo N ${ }^{\circ}$ 084-2007-EF, tienen por finalidad brindar incentivos para la ejecución de proyectos correspondientes a distintos sectores productivos a través del otorgamiento de beneficios tributarios. Así, el Régimen Especial de Recuperación Anticipada del IGV consiste en la devolución del IGV que gravó las importaciones y/o adquisiciones locales de bienes de capital nuevos, bienes intermedios nuevos, servicios y contratos de construcción, realizados en la etapa preproductiva, a ser empleados por los beneficiarios del régimen directamente para la ejecución de los proyectos previstos en los contratos de inversión respectivos y que se destinen a la realización de operaciones gravadas con el IGV o exportaciones.

La norma considera como beneficiarios a las personas naturales o jurídicas que se encuentran en la etapa preproductiva del proyecto (obra o actividad económica a realizar), que suscriban un contrato de inversión para la realización de dicho proyecto y que cuenten con la calificación para el goce del referido régimen. En efecto, podrán acogerse a dicho régimen las personas naturales o jurídicas que realicen inversiones en cualquier sector de la actividad económica que genere renta de tercera categoría, y que cumplan con los siguientes requisitos:

- Suscribir un Contrato de Inversión con el Estado para realizar inversiones no menores a US\$ 5 millones en el proyecto.

- Contar con un proyecto que requiera de una etapa preproductiva igual o mayor a dos (2) años, contados a partir de la fecha de inicio del cronograma de inversiones contenido en el Contrato de Inversión.

La etapa preproductiva es el período anterior al inicio de operaciones. En el caso de la minería, se considerará que los beneficiarios del régimen han iniciado la explotación del proyecto, cuando realicen la primera exportación de un bien o servicio, o la primera transferencia de un bien o servicio gravado con el IGV, que resulten de dicha explotación, así como cuando perciban cualquier ingreso gravado con el IGV que constituya el sistema de recuperación de las inversiones en el proyecto, incluidos los costos o gastos de operación o el mantenimiento efectuado. El Ministerio de Energía y Minas (MINEM) controla la ejecución de los Contratos de Inversión e informa periódicamente a la SUNAT sobre los mismos. A la fecha, once (11) empresas tienen suscritos contratos en etapa preproductiva o preoperativa (construcción y desarrollo) y dos (02) se encuentran en trámite. ${ }^{27}$

27 Anuario Minero 2017, editado por el Ministerio de Energía y Minas, primera edición, 30 de abril de 2018, 40. 


\subsection{Inversión minera}

Las inversiones mineras se clasificaban en 7 rubros: equipamiento de planta de beneficio, equipamiento minero, exploración, explotación, infraestructura, preparación, y otros. Ello, debido a que los titulares mineros reportaban sus inversiones bajo estas categorías definidas en la Declaración Estadística Mensual (ESTAMIN). Sin embargo, el 01 de marzo de 2018 mediante Resolución Directoral Nº059-2018-MEM/DGM, se reestructuró el formato de la Declaración Estadística Mensual (ESTAMIN), reclasificando las inversiones mineras en 6 rubros: desarrollo y preparación, equipamiento minero, exploración, infraestructura, planta beneficio, y otros.

En el Perú, entre los años 2008 y 2017, puede denominarse como la década de las "Inversiones en Megaproyectos Mineros", lo cual se sustenta en el hecho de que nunca antes en la historia de la minería peruana se ha registrado un flujo de inversiones de tal magnitud.

Desde que se tiene información en la base de datos de inversiones mineras del Ministerio de Energía y Minas (1996) hasta el año 2017, las inversiones reportadas por los titulares mineros ascendieron a US\$ 60273 millones, de los cuales US\$ 51794 millones (85,9 \%) corresponden a la década del 2008 al 2017, que ha permitido consagrar al Perú como un país minero.

En esta década, se puede apreciar tres etapas bien definidas. Una primera etapa de inversiones crecientes donde se iniciaron y desarrollaron importantes proyectos mineros como Las Bambas (Apurímac), Ampliación Cerro Verde (Arequipa), Antapaccay (Cusco), Toromocho (Junín), Constancia (Cusco), entre otros, período en que las inversiones mineras ascendieron a US\$ 29629 millones (entre 2008 y 2013). La segunda etapa comprende un período de inversiones decrecientes entre los años 2014 y 2016, que consolida y cierra el ciclo de estos proyectos, al pasar progresivamente de megaproyectos a megaunidades productivas; si bien es cierto que se nota una disminución en el monto de inversiones, estas han sido de gran magnitud que ascendieron a US\$ 18237 millones. La tercera etapa inicia en el 2017, ańo en que las inversiones mineras ascendieron a US\$ 3928 millones, esperando que sea el primer escalón de un nuevo ciclo de crecimiento debido a los proyectos mineros que actualmente se encuentran en construcción como Ampliación Toquepala, Ampliación Marcona y Ampliación Shahuindo (fase II) así como los próximos a iniciarse en el 2018. Las inversiones mineras en el 2017 registraron un crecimiento de 17,8 \% respecto del 2016, situación que no se presentaba desde hace 4 ańos. ${ }^{28}$

28 Anuario Minero 2017, editado por el Ministerio de Energía y Minas, primera edición, 30 de abril de 2018, 45. 
Este incremento en la inversión responde a la mejora en los precios de los metales, que han permitido mejorar el balance de las empresas y destinar más fondos a la inversión en infraestructura y exploraciones, que habían estado rezagadas en los últimos años producto de la caída de los metales. Sobre el particular, es preciso señalar que el incremento en las inversiones en exploración es fundamental toda vez que son la base para el desarrollo de nuevos proyectos mineros. En el 2017, el presupuesto mundial en exploraciones fue de US\$ 8400 millones, significando un incremento de $15 \%$ con respecto al año 2016 (US\$ 7300 millones), después de 4 años consecutivos de caída. Asimismo, el Perú ingresó al top 5 mundial en exploración minera, logrando captar el $7 \%$ del presupuesto global en exploración minera. De esta forma, el país se posicionó en el segundo lugar a nivel latinoamericano, ubicándose solo detrás de Chile, que captó el $8 \%$ de este presupuesto. En este contexto, el Perú se encuentra próximo a alcanzar la meta propuesta que consiste en captar el $8 \%$ de la inversión global en exploraciones al 2021. ${ }^{29}$

La tendencia creciente de las inversiones mineras sumada a la actual mejora de los precios internacionales de nuestros principales productos mineros perfila un buen futuro para la actividad minera.

\section{APORTE ECONÓMICO-SOCIAL DE LA ACTIVIDAD MINERA}

\subsection{Canon minero}

El canon es la participación de la que gozan los Gobiernos locales (municipalidades provinciales y distritales) y los Gobiernos regionales del total de ingresos y rentas obtenidos por el Estado, por la explotación económica de los recursos naturales. ${ }^{30}$

El denominado canon minero, como las demás modalidades de canon de los diversos sectores (minerales, hidrocarburos, gas, hidroelectricidad, pesca, forestal, y fauna silvestre), implica, en síntesis, una redistribución del Impuesto a la Renta entre Gobierno central y los Gobiernos regionales y locales donde esos recursos naturales se encuentran ubicados.

El ordenamiento jurídico establece que el canon ha sido previsto constitucionalmente en el artículo $77^{\circ}$, como el reconocimiento del derecho que les asiste a los Gobiernos locales y regionales para recibir una porción de lo recaudado en beneficio de su comunidad; debiendo calcularse sobre la base de la totalidad de ingresos y rentas provenientes de la explotación de recursos naturales de sus circunscripciones. ${ }^{31}$

29 Según el reporte WorldExplorationTrends 2018 elaborado por S\&P Global MarketIntelligence, acceso el 15 de agosto del 2018, https://pages.marketintelligence.spglobal.com/World-Exploration-Trends-Report-2018-MS.html

30 Gaceta Jurídica, La Constitución comentada. Tomo I (Lima: Gaceta Jurídica, 2006), 1012.

31 Resolución del Tribunal Constitucional 0048-2004-PI/TC Pleno Jurisdiccional, 26. 
Estos ingresos por canon minero permiten a los Gobiernos subnacionales contar con recursos para promover las inversiones a fin de mejorar la calidad de vida de la población.

La constitución del canon minero se da por el 50 \% del Impuesto a la Renta que pagan las empresas mineras por el aprovechamiento de los recursos minerales (metálicos y no metálicos).

Las transferencias de recursos generados por la minería hacia las regiones en el 2017, por concepto de canon minero, regalías mineras y pago por derecho de vigencia y penalidad, ascendieron a 3303 millones de soles, incrementándose un $26,50 \%$ con respecto al 2016 ( 2 611 millones de soles). Las regiones que se vieron más beneficiadas por el mayor valor de las transferencias de recursos generados por la actividad minera fueron Áncash, con una participación del 22,70\% (750,9 millones de soles); Arequipa con $16 \%$ (528,52 millones de soles); La Libertad con 9,60 \% (317,73 millones de soles); Apurímac con 9,40 \% (312,01 millones de soles) y Cajamarca con 7,30 \% (241,77 millones de soles). ${ }^{32}$

A continuación, se podrá observar las transferencias realizadas durante los 23 años por concepto de Canon Minero ascendiendo un total de S/. 44,999 millones $^{33}$.

\subsection{Regalías mineras}

La regalía minera es una contraprestación económica establecida por ley, mediante la cual los titulares (también cesionarios) de concesiones mineras están obligados a pagar mensualmente al Estado por la explotación de los recursos minerales metálicos y no metálicos. ${ }^{34}$

Son sujetos obligados al pago de la regalía minera, los titulares de las concesiones mineras, incluyendo a las empresas integradas que realicen actividades de explotación de recursos minerales metálicos o no metálicos, o los cesionarios que realizan dichas actividades según lo establecido en el Título Décimo Tercero del Texto Único Ordenado de la Ley General de Minería.

Los proyectos mineros que hubieran pactado regalías mineras antes de la vigencia de la Ley de Regalías Mineras se rigen por sus contratos, así como los que a la fecha de vigencia de la Ley de Minería se encuentren en proceso de licitación, se rigen por sus respectivas bases aprobadas por PROINVERSIÓN.

32 Andina, “Transferencias a regiones por canon minero y regalías sumaron S/ 3303 millones el 2017”, Andina, 8 de jun de 2018, sección Minería en el Perú, acceso el 16 de agosto de 2018, https://andina.pe/agencia/noticia-transferencias-a-regiones-canon-minero-y-regalias-sumaron-s-3303-millones-2017-712698.aspx

33 Sociedad Nacional de Minería, Petróleo y Energía, "Reporte Canon Minero 2018”, Sociedad Nacional de Minería Petróleo y Energía, 2018, acceso el 16 de agosto de 2018, http://www.snmpe.org.pe/informes-y-publicaciones/canon/canon-minero/5308-reporte-canon-minero-2018.html, 1-34.

34 Superintendencia Nacional de Aduanas y de Administración Tributaria (SUNAT), "Regalía Minera", SUNAT (2018), acceso el 16 de agosto de 2018, http://www2.sunat.gob.pe/pdt/pdtModulos/independientes/regaliaMinera/index. html 
Mediante la Ley $\mathrm{N}^{\circ} 28258$ de fecha 3 de junio de 2004, modificada en algunos de sus artículos por la Ley $\mathrm{N}^{\circ} 28323$ del 23 de julio de 2004 , se estableció un nuevo gravamen denominado Regalía Minera, aplicable únicamente a los concesionarios mineros, con excepción de los pequeños productores mineros y productores mineros artesanales. Este gravamen seńala que los titulares de las concesiones mineras pagan al Estado una contraprestación económica por la explotación de los recursos minerales, metálicos y no metálicos, calculada en base a un porcentaje incremental sobre el valor del concentrado o su equivalente, conforme a la cotización de los precios en el mercado internacional, para cuyo efecto se tuvieron en cuenta los siguientes rangos de ingresos: a) primer rango, hasta US\$ 60 millones anuales: $1 \%$; b) segundo rango: por el exceso de USS 60 millones hasta USS 120 millones: $2 \%$; tercer rango: sobre el exceso de US\$ 120 millones, $3 \%$.

En el caso de los minerales que no tienen cotización internacional (como podría ser el caso de los minerales no metálicos) la regalía es del 1\% "sobre el componente minero". El importe pagado por las empresas en concepto de la Regalía Minera fue considerado como costo deducible en el año fiscal correspondiente. Los aspectos de detalle de la aplicación de ambas leyes fueron materia de su Reglamento aprobado por Decreto Supremo N ${ }^{\circ} 157-20$ EF de fecha 11 de noviembre de 2004, modificado por el Decreto Supremo 018-2005-EF. Si bien los índices de Distribución, así como el tipo de cambio de referencia iban a ser fijados periódicamente por Resolución Ministerial del sector de Economía y Finanzas, como en efecto así viene ocurriendo (Resoluciones Ministeriales $\mathrm{N}^{\circ}$ 015-2007-EF/15. 019-2007-PCM y 109-2007-EF/15 fechas 19 de enero, 29 de enero y 28 de febrero de 2007, respectivamente, para solo citar algunas). ${ }^{35}$

\subsection{Derecho de vigencia y penalidad}

El primer pago del Derecho de Vigencia es requisito para la formulación de un nuevo petitorio minero, ya sea este formulado en el INGEMMET o en los Gobiernos regionales. ${ }^{36}$ El pago del Derecho de Vigencia y/o Penalidad se efectuará sobre la base del Padrón Minero Nacional actualizado al 31 de diciembre de cada ańo, en las entidades financieras autorizadas. Estos pagos se deben realizar desde el primer día hábil del mes de enero al 30 de junio de cada año, proporcionando a las entidades financieras el CÓDIGO ÚNICO de su derecho minero.

Para mejorar la explicación sobre el derecho de vigencia, precisamos que es una retribución económica por el mantenimiento de la concesión minera, y cuyo incumplimiento priva de efecto a la concesión misma, constituyéndose en causal de caducidad de la concesión. El derecho de vigencia, tiene una periodicidad anual y para tal efecto, se tomará en cuenta el

35 Martín Belaunde Moreyra, Derecho minero y concesión (Lima: Editorial San Marcos E. I. R. L, 2013), 250.

36 Instituto Geológico, Minero y Metalúrgico (INGEMET), “¿Cómo pagar derecho de vigencia y penalidad?”, INGEMET (2018), acceso el 16 de agosto de 2018, http://www.ingemmet.gob.pe/como-pagar-derecho-de-vigencia-y-penalidad 
número de hectáreas otorgadas o solicitadas en concesión, y no la producción obtenida, como en el caso de la regalía minera.

Tanto la regalía minera con el derecho de vigencia se diferencian, lo cual es también contemplada por la propia Ley Orgánica para el Aprovechamiento Sostenible de los Recursos Naturales; su artículo 29\%, al establecer las condiciones del aprovechamiento sostenible, estipula de manera independiente, por un lado, que se cumpla con la retribución económica correspondiente de acuerdo a las leyes especiales (literal d); y, por otro, que se mantenga al día el derecho de vigencia (literal e). Tal como quedó dicho al analizar el supuesto alegado de inconstitucionalidad formal, el artículo $20^{\circ}$ de esta ley orgánica es el que establece las diferentes retribuciones económicas a que tiene derecho el Estado por la explotación de sus recursos naturales no renovables, diferenciando el derecho de vigencia de otras contraprestaciones. ${ }^{37}$

\subsection{Recaudación bajo el nuevo régimen tributario minero}

El Congreso de la República aprobó recientemente que los Gobiernos regionales y locales puedan utilizar los recursos del canon para el financiamiento de proyectos de vivienda social a través del Programa Techo Propio con el beneficio del Bono Familiar Habitacional (BFH) y del Programa Nacional de Vivienda Rural (PNVR). La finalidad de la modificación de la ley busca cerrar la brecha de vivienda, cuyo déficit es de un millón de 860 mil en los sectores más pobres del país. ${ }^{38}$

\subsection{Inversión social y desarrollo sostenible}

En el caso de los Gobiernos locales, los recursos de canon minero se utilizarán en gastos de inversión en cumplimiento del Sistema Nacional de Programación Multianual y Gestión de Inversiones, denominado ahora Invierte.pe. Por su parte, de acuerdo a la distribución se deberá destinar el $30 \%$ del monto que le corresponda a la inversión productiva para el desarrollo sostenible de las comunidades donde se extrae dicho recurso natural.

Por otra parte, en el caso de los Gobiernos regionales, los recursos obtenidos se utilizarán para el financiamiento o cofinanciamiento de proyectos u obras de infraestructura de impacto subnacional.

Tanto los Gobiernos locales como regionales están facultados a utilizar hasta un $20 \%$ del canon minero para el mantenimiento de los proyectos de inversión pública priorizando infraestructura básica, así como hasta otro $5 \%$ para financiar la elaboración de perfiles y eva-

37 Sentencia del Tribunal Constitucional recaída en el Expediente Nº048-2004-PI/TC, 13.

38 Congreso de la República de Perú, "Modifican ley del canon para financiamiento de vivienda social", Congreso de la República de Perú, acceso el 16 de agosto de 2018, http://www.congreso.gob.pe/index.php?K=263\&id=11859/noticias/ MODIFICAN-LEY-DEL-CANON-PARA-FINANCIAMIENTO-DE-VIVIENDA-SOCIAL\#.W3ej6dJKiUk 
luar los estudios de preinversión. Adicionalmente, los Gobiernos locales y regionales pueden utilizar los recursos para proyectos orientados a brindar servicios públicos (infraestructura para comisarías, postas médicas, penales, etc.).

Por lado, también se aprovecha el canon minero para el financiamiento de obras de infraestructura que beneficien a la región. Por ejemplo: comisarías, penales, escuelas, postas médicas, entre otros. Cabe destacar, sobre el porcentaje que reciben las universidades nacionales, que son principalmente destinados a la investigación científica de la salud pública y biodiversidad.

\subsection{Gestión de los fondos sociales}

Los fondos sociales priorizan proyectos de atención humanitaria, infraestructura, servicios básicos, capacitación, fortalecimiento de capacidades, así como financiamiento de proyectos para la generación de empleo productivo para la población, principalmente de los sectores más vulnerables. Según el Ministerio de Energía y Minas, desde el 2006, los fondos sociales en la minería peruana acumularon un total de S/ 1 680,72 millones en beneficio de muchas comunidades aledańas a los proyectos mineros en todo el país.

El Informativo Minero del MEM señala que los fondos sociales en minería creados mediante el Decreto Legislativo $\mathrm{N}^{\circ} 996$ incluyen recursos conformados por un porcentaje de la transferencia de proyectos mineros de titularidad del Estado, que tienen como finalidad financiar proyectos sociales que beneficien a la población aledańa a los proyectos mineros.

De acuerdo con la norma, estos recursos son distribuidos en un $85 \%$ entre los centros poblados o comunidades; un $10 \%$ entre las municipalidades distritales y un $5 \%$ entre las municipalidades provinciales de las zonas aledañas a los proyectos mineros.

\section{OTRAS TRANSFERENCIAS DEL GOBIERNO CENTRAL}

El canon y las regalías mineras no son las únicas transferencias que realiza el Gobierno central a los Gobiernos locales y regionales. El canon minero es el más importante de los seis tipos de canon existentes en el Perú (minero, petrolero, gasífero, hidroenergético, forestal y pesquero), debido al volumen de recursos que genera para las zonas donde se distribuye.

Así tenemos:

- El canon hidroenergético es la participación de la que gozan los Gobiernos regionales y locales sobre los ingresos y rentas obtenidos por el Estado por la utilización del recurso hídrico en la generación de energía eléctrica.

- El canon gasífero es la participación que perciben las circunscripciones donde está ubicado geográficamente el recurso natural sobre los ingresos que percibe el Estado en la explotación de gas natural y condensados. 
- El canon pesquero es la participación de la que gozan las circunscripciones sobre los ingresos y rentas obtenidos por el Estado por la explotación de los recursos hidrobiológicos provenientes de las empresas dedicadas a la extracción comercial de pesca de mayor escala de recursos naturales hidrobiológicos de aguas marítimas y continentales, lacustres y fluviales, y de aquellas empresas que además de extraer estos recursos se encarguen de su procesamiento.

- El canon forestal es la participación de la que gozan las circunscripciones del pago de los derechos de aprovechamiento de los productos forestales y de fauna silvestre, así como de los permisos y autorizaciones que otorgue la autoridad competente.

Las transferencias que reciben los Gobiernos regionales y locales por parte del Gobierno central se cuentan también:

- El Fondo de Compensación Municipal (FONCOMUN) históricamente ha sido la transferencia más importante que reciben las municipalidades y que ha sido empańada en los últimos ańos por el aumento del canon. Como su nombre lo indica, esta transferencia debe compensar. Actualmente solo lo hace por pobreza. Sin embargo, es importante que el FONCOMUN tome en cuenta entre sus factores de distribución, el canon que reciben algunas municipalidades. Esto implica que si una municipalidad recibe recursos por canon reciba algo menos de FONCOMUN, lo cual no quiere decir que si recibe 100 más de canon se le quite 100 de FONCOMUN; pero sí alguna proporción que no debería superar el $50 \%$.

- El Fondo de Desarrollo Socioeconómico de Camisea (FOCAM): fondo intangible destinado al desarrollo de los departamentos por donde pasan los principales ductos del gas de Camisea. Fue creado en el año 2004, está compuesto por el $25 \%$ de lo que corresponde al Gobierno central de las regalías provenientes de los lotes 88 y 56 (gas de Camisea), luego de efectuado el pago gasífero y otras deducciones. ${ }^{39}$

- La Renta de Aduanas, ingreso que se deriva de la recaudación de las aduanas marítimas, aéreas y postales del país.

\section{POLÍTICAS PARA LA ADECUADA APLICACIÓN DEL CANON Y REGALÍAS MINERAS}

\subsection{Cuestión previa}

Como hemos señalado, debemos analizar primero el entorno macroeconómico que atravesará el Perú antes de proponer medidas de política en canon y regalías mineras, y más aún

39 Beatriz Boza, “Canon Minero: ¿caja chica o palanca para el desarrollo?”, CAD Ciudadanos al día, Perú (2016): 20. 
cuando el escenario que estamos viviendo frente a una democracia débil y a la corrupción ha generado inestabilidad e incertidumbre y sobre todo la paralización de diversos proyectos de inversión, los cuales traerían consigo una reducción significativa en la recaudación del canon minero y regalías mineras sin contar con la inestabilidad y volatilidad de los precios de los metales en el mercado internacional. Para ello sugerimos medidas de políticas en los siguientes puntos claves:

- Mayor transparencia en la asignación y el uso de los recursos del canon y de las regalías mineras.

- Mejorar las capacidades locales en gestión pública con mayor incidencia en elaboración de proyectos y vigilancia ciudadana.

- Mayor coordinación entre las instituciones del Estado involucradas, que involucran a las públicas, las empresas privadas y la misma población.

- Mayor responsabilidad de las autoridades, quienes deben ser debidamente fiscalizados en el desempeño de sus funciones.

Partiendo de que las transferencias efectuadas por el Gobierno central tiene como finalidad promover el desarrollo económico y social de las regiones donde se realizan actividades que generan ingresos al Estado y compensar insuficiencias en la generación de ingresos propios, se debe hacer un análisis de redistribución que llegue a aquellas regiones donde no se desarrollen actividades que generen ingresos para el Estado. En ese contexto coincidimos con el Centro de Estudios sobre Minería y Sostenibilidad de la Universidad del Pacífico, que ha desarrollado una propuesta metodológica que permite realizar transferencias compensatorias adicionales bajo criterios de asignación prioritaria a las circunscripciones que relativamente cuentan con menores recursos del canon, regalías, renta de aduanas y FOCAM; y que a la vez tienen altos porcentajes de población en condición de pobreza y por tanto, tienen mayores necesidades básicas insatisfechas.

Con esta metodología de "redistribución", se busca la superación de las inequidades existentes en la distribución de los recursos provenientes de la explotación económica de los recursos naturales.

El Estado debe plantear estrategias que reduzca los desbalances horizontales mientras exista la abundancia de recursos por explotación de minerales producto de los buenos precios internacionales. Sin embargo, no debe atentar contra los derechos adquiridos bajo la Constitución Política y específicamente la Ley del Canon que respalda el criterio de propiedad según ubicación geográfica de los recursos. De esta manera, la propuesta resulta viable en materia técnica, bajo la legislación vigente y los principios de equilibrio fiscal. 
Los criterios de distribución que se aplicaría se sustentarían en criterios de equidad y compensación determinando la prioridad en base a variables de pobreza y vulnerabilidad de las regiones que reciben menores ingresos derivados de la explotación de recursos naturales o que mantienen menores recursos por concepto de saldo de balance.

La metodología implica la clasificación explícita de los distritos en base a dos indicadores:

A. Indicador de pobreza: En base a un indicador de pobreza definido por la Tasa de Carencia de la población de servicios básicos (luz, agua y desagüe) y la Tasa de Pobreza Extrema; se clasifica cada distrito según su ubicación en la distribución del indicador, estableciendo como distritos 'no prioritarios' a aquellos distritos ubicados en el último decil y como 'prioritarios' a los ubicados en los deciles restantes.

B. Indicador de transferencias: Corresponde a la clasificación según los niveles de recursos transferidos, incluyendo una variable que registra la eficiencia en el gasto que está determinado por la acumulación de los saldos de balance de cada Gobierno local. De esta forma, el indicador está determinado por la suma de los recursos provenientes de las transferencias de CANON, Renta de Aduanas, FOCAM y Regalías; añadiéndose a este total el saldo de balance del año anterior. Este indicador está expresado en términos per cápita para corregir por diferencia de población.

Con estos dos indicadores se construye un indicador final que asigne la prioridad a únicamente aquellos distritos que sean prioritarios en ambos indicadores. Basados en este indicador se calcula la probabilidad de ser prioritario según los indicadores anteriores, obteniendo con ello la probabilidad para cada distrito y con ello la construcción del indicador de distribución de los recursos adicionales.

\subsection{Creación de un fondo subnacional (a nivel regional y municipal)}

El Gobierno Nacional cuenta con un fondo de estabilización subnacional cuya función es ser empleado cuando se necesite aumentar el gasto público ante una recesión. Del mismo modo, se debería lograr que las municipalidades y Gobiernos regionales que reciben canon cuenten con uno. Así, cuando este tenga un crecimiento fuerte o se ejecute por debajo de un porcentaje mínimo, los excedentes vayan a una cuenta a la cual se pueda acceder cuando haya una caída significativa en el flujo de estos recursos.

Con esta medida podemos reducir la volatilidad fiscal generada por la variabilidad en el ingreso recibido del canon e introducir una política de incentivo por una mejor ejecución de los recursos (gasto eficiente de los recursos). 


\subsection{Crear un mecanismo para compensar las diferencias horizontales en la distribución de recursos:}

El mecanismo estaría orientado a que el Gobierno Nacional podría asignar algunos recursos adicionales a un fondo creado para compensar diferencias horizontales entre los Gobiernos regionales y locales y así disminuir los reclamos que llegan a él por temas de inequidad en la distribución fiscal. Debemos manifestar que una adecuada gestión de distribución de riquezas generará confianza en la población, además de una adecuada supervisión en el gasto.

Estos recursos deberían utilizarse para compensar disparidades en aquellas jurisdicciones que no reciben canon, como, por ejemplo, las regiones Amazonas, Loreto, Tumbes y Ucayali. Cabe señalar que justo en aquellas regiones donde no hay explotación de recursos presentan altos índices de pobreza; por eso debemos señalar un mecanismo que ayude a equiparar estos desniveles en la distribución.

Con este modelo lograríamos reducir las disparidades que genera la distribución del canon, debido que los recursos liberados bajo este mecanismo de compensación irían a aquellas zonas que no reciben canon y así se lograría compensar disminuyendo la inequidad fiscal.

\subsection{Sancionar la mala ejecución del canon}

Somos conscientes de que si la calidad de la inversión financiada a través del canon es baja, entonces se debe castigar al Gobierno local moviendo una proporción de los ingresos por canon a su fondo de estabilización o bloquear el gasto en un porcentaje, una especie de ahorro forzoso.

No se les quitará los recursos, solo se les prohíbe su uso hasta cuando llegue la época de "déficit", mientras el Estado capacita y profesionaliza a sus funcionarios, o de otro lado, los recursos para las evaluaciones de la inversión podrían cofinanciarse entre el Gobierno Nacional y los subnacionales.

Con este modelo generaríamos una política de incentivo para la inversión de calidad y generar fondos de contingencia para cuando caigan los recursos fiscales por canon.

\section{CONCLUSIONES}

a. Los recursos naturales constituyen todo aquello que encontramos en la naturaleza y que el ser humano puede utilizar para beneficiarse económicamente y para satisfacer sus pretensiones. Su clasificación es de renovables y no renovables, efectuándose esta distinción en función a la tasa de generación o regeneración y cantidad de consumo de ellos. 
b. El Perú ha adoptado el sistema dominalista para la explotación de los minerales. En tal sentido, el Estado es el dueńo de estos recursos naturales, y mediante normativa los otorga a terceros mediante la figura jurídica de la concesión minera, para que unido a otros requerimientos de orden ambiental y administrativo pueda efectuarse la explotación de los minerales, conforme se interpreta en el artículo $66^{\circ}$ de la Constitución Política.

c. Nuestro país goza de una larga tradición minera en América Latina y el mundo; es el segundo productor de cobre, plata y zinc a nivel mundial. En América Latina, ocupa el primer lugar en la producción de oro, zinc y plomo. Posee las mayores reservas de plata del mundo y se ubica en tercer lugar en reservas de cobre a nivel mundial. En Latinoamérica lidera el ranking en reservas de plomo, zinc y molibdeno. Ello refleja su enorme potencial mineralógico.

d. En el Perú, entre los años 2008 y 2017, puede denominarse como la década de las "Inversiones en Megaproyectos Mineros", lo cual se sustenta en el hecho de que nunca antes en la historia de la minería peruana se ha registrado un flujo de inversiones de tal magnitud.

e. La actividad minera tiene un papel importante en la economía peruana, ha experimentado un importante dinamismo que se reflejó en la provisión de divisas a la economía, la generación de ingresos fiscales por impuestos, regalías mineras, canon, la creación de empleos directos e indirectos, y el incremento del crecimiento potencial de la economía.

f. El canon minero ha sido previsto constitucionalmente en el artículo $77^{\circ}$, como el reconocimiento del derecho que le asiste a los Gobiernos locales y regionales para recibir una porción de lo recaudado en beneficio de su comunidad; debiendo calcularse, sobre la base de la totalidad de ingresos y rentas provenientes de la explotación de recursos naturales de sus circunscripciones.

g. El Congreso de la República aprobó en 2018, que los Gobiernos regionales y locales puedan utilizar los recursos del canon para el financiamiento de proyectos de vivienda social a través del Programa Techo Propio con el beneficio del Bono Familiar Habitacional (BFH) y del Programa Nacional de Vivienda Rural (PNVR).

h. Dentro de los problemas en función a la utilización del canon minero tenemos: (1) Falta de implementación de nuevas Políticas; (2) No existe un Fondo Subnacional; (3) Diferencias horizontales en la distribución del canon; (4) La inexistencia de un ente supervisor y fiscalizador exclusivo para el canon minero; (5) La Ley del Canon y su distribución no brinda equidad. 


\section{RECOMENDACIONES}

a. La corrupción ha generado inestabilidad e incertidumbre y paralización de diversos proyectos de inversión y la consiguiente reducción en recaudación de canon minero y regalías mineras. Por ello, proponemos medidas de políticas en los siguientes puntos claves:

Mayor transparencia en la asignación y el uso de los recursos del canon y de las regalías mineras.

$\checkmark$ Mejorar las capacidades locales en gestión pública con mayor incidencia en elaboración de proyectos y vigilancia ciudadana.

$\checkmark$ Mayor coordinación entre las instituciones del Estado involucradas, que involucran a las públicas, las empresas privadas y la misma población.

b. La Creación de un Fondo Subnacional, donde las municipalidades y Gobiernos regionales que reciben canon cuenten con un fondo de estabilización. Así, cuando este tenga un crecimiento fuerte de la actividad minera o se ejecute por debajo de un porcentaje mínimo, los excedentes estén en una cuenta a la cual se pueda acceder cuando exista caída significativa en el flujo de estos recursos. Con esta medida podemos reducir la volatilidad fiscal generada por la variabilidad en el ingreso recibido del canon e introducir una política de incentivo por una mejor ejecución de los recursos (gasto eficiente de los recursos).

c. Creación de mecanismos para compensar las diferencias horizontales en la distribución de recursos, orientado a que el Gobierno Nacional podría asignar algunos recursos adicionales a un fondo creado para compensar diferencias horizontales entre los gobiernos regionales y locales y así disminuir los reclamos que llegan a él por temas de inequidad en la distribución fiscal.

d. Creación de un ente independiente que supervise, fiscalice y sancione a quienes realizan una deficiente labor. Esta situación, llevaría a proponer un replanteamiento entre el Estado y sus organismos para que se refleje que donde existe actividad minera concurre el progreso, revirtiendo sobre la población la sensación de pobreza que a la fecha no difiere entre los que viven en zonas mineras y las que no tienen esta actividad.

e. Reformular la Ley del Canon de la siguiente forma: (1) Distrito Productor: $10 \%$ (2) Municipios en el departamento productor: $65 \%$ (2) Gobierno Regional: 20\% (2) Universidades en el departamento productor: 5\%. Este nuevo esquema de reparto lograría una dosificación más equitativa dentro de los departamentos. 


\section{REFERENCIAS}

- Andina. "Transferencias a regiones por canon minero y regalías sumaron S/ 3,303 millones el 2017”. Andina, 8 de jun de 2018, sección Minería en el Perú. Acceso el 16 de agosto de 2018. https://andina.pe/agencia/noticia-transferencias-a-regiones-canon-minero-y-regalias-sumaron-s-3303-millones-2017-712698.aspx

- Anuario Minero 2017. Editado por el Ministerio de Energía y Minas. Primera edición, 30 de abril de 2018.

- Aranzamendi, Lino; Huamán, Julio. Minería: potencialidad, problemática, Derecho y Legislación. Lima, Perú: Editora Jurídica Grijley, 2015.

- Arias, Elva. "Las mesas de desarrollo son una buena iniciativa del Gobierno". Revista Horizonte Minero, Revista Internacional de Minería y Energía, n. 91 (Año 14, setiembre 2013).

- Artículo 3 de la Ley $N^{\circ} 26821$ - Ley Orgánica para el aprovechamiento sostenible de los recursos naturales. Acceso el 18 de agosto. http://www.ana.gob.pe/media/95192/ ley_26821.pdf

- Basadre Ayulo, Jorge. Derecho Minero Peruano. Lima: Editora y Distribuidora Grijley, 1990.

- Belaunde Moreyra, Martín. Derecho Minero y Concesión. Lima: Editorial San Marcos E. I. R. L, 2013.

- Boza, Beatriz. "Canon Minero: ¿Caja chica o palanca para el desarrollo?”. CAD Ciudadanos al día, Perú (2016).

- Congreso de la República de Perú. "Modifican ley del canon para financiamiento de vivienda social”. Congreso de la República del Perú. Acceso el 16 de agosto de 2018._http://www. congreso.gob.pe/index.php?K=263\&id=11859/noticias/MODIFICAN-LEY-DEL-CANON-PARA-FINANCIAMIENTO-DE-VIVIENDA-SOCIAL\#.W3ej6dJKiUk

- Dourojeam, Marc J. "Recursos naturales, desarrollo y conservación en el Perú". En La Constitución comentada. Tomo II. Lima: Gaceta Jurídica.

- "El uso sostenible de los recursos naturales". Guía metodológica: el desarrollo sostenible y el ordenamiento territorial. Proyecto, ordenamiento participativo del territorio y de los recursos naturales en los Andes peruanos. Módulo II. Acceso el 18 de agosto del 2018. http:// ongadg.be/bibliadg/bibliotheque/opac_css/doc_num/fiches_techniques/guia_del_facilitador_modulo_2.pdf

- Jared Diamond. Colapso. 6a edición. España: Liberduplex S. L. U.

- Lastres, Enrique. "Los recursos naturales en la Constitución vigente". Ius et Veritas, Revista editada por estudiantes de la Facultad de Derecho de la Pontificia Universidad Católica del Perú, n. 9 (Año V). 
- Gallegos, Armando; Ali Díaz y Andrea Nieto. Minería: retos y posibilidades. Planificación estratégica del sector minero en el Perú y benchmark con seis países mineros. Lima, Instituto de Ingenieros de Minas del Perú, 2017.

- Instituto Geológico, Minero y Metalúrgico (INGEMET). “¿Cómo pagar derecho de vigencia y penalidad?”. INGEMET (2018). Acceso el 16 de agosto de 2018. http://www. ingemmet.gob.pe/como-pagar-derecho-de-vigencia-y-penalidad

- Medrano, Isabel; Jessica Obeso. La concesión minera: aprovechamiento de recursos minerales, limitaciones legales y propuesta normativa. Lima: Grupo Editorial Lexus\& Iuris, 2018. 2018.

- Ministerio de Agricultura, Portal del MINAGRI. Acceso 15 de agosto del 2018. http://www.minagri.gob.pe/portal/41-sector-agrario/recursos-naturales/314-introduccion https://doi.org/10.2307/j.ctv5jxmhh.5

- Naciones Unidas. Recursos naturales de los paises en desarrollo, investigación, explotación y utilización racional. Departamento de Asuntos Económicos y Sociales, 1970.

- Organismo Supervisor de la Inversión en Energía y Minería - OSINERGMIN, “¿Cómo se clasifica la actividad minera en el Perú?”. Acceso el 18 de agosto del 2018. http://www. osinergmin.gob.pe/mineria/actividad_minera/clasificacion-minera-peru

- "Recursos Renovables". Zona Económica. Acceso 16 de agosto del 2018. http://www.zonaeconomica.com/recursos-renovables

- Reporte WorldExplorationTrends 2018 elaborado por S\&P Global MarketIntelligence. Acceso el 15 de agosto del 2018. https://pages.marketintelligence.spglobal.com/WorldExploration-Trends-Report-2018-MS.html

- Sociedad Nacional de Minería, Petróleo y Energía. "Reporte Canon Minero 2018”. Sociedad Nacional de Minería Petróleo y Energía, 2018. Acceso el 16 de agosto de 2018. http://www.snmpe.org.pe/informes-y-publicaciones/canon/canon-minero/5308-reporte-canon-minero-2018.html

- Superintendencia Nacional de Aduanas y de Administración Tributaria (SUNAT), "Regalía Minera”. SUNAT (2018). Acceso el 16 de agosto de 2018. http://www2.sunat.gob.pe/ $\mathrm{pdt} / \mathrm{pdtModulos/independientes/regaliaMinera/index.} \mathrm{html}$

- Westreicher, Carlos Andaluz. Manual de derecho ambiental. $1^{a}$ edición. Edición Proterra, 2006.

RECIBIDO: $21 / 08 / 2018$

APROBADO: 20/09/2018 